\title{
DISCURSO PROFERIDO PELO PROF. DR. JOSÉ AFONSO DA SILVA POR OCASIÃO DO RECEBIMENTO DO COLAR DO MÉRITO JUDICIÁRIO ${ }^{1}$
}

Exmo. Sr.

Dr. Márcio Martins Bolinha

DD. Presidente do Tribunal de Justiça do Estado de São Paulo.

Exmos. Srs. Desembargadores deste Tribunal de Justiça.

Exmo. Sr. Dr. Rubens Approbato Machado

DD. Presidente da $\mathrm{OAB} / \mathrm{SP}$, a quem agradeço as generosas palavras proferidas aqui a meu respeito.

Exmo. Sr. Dr. Visconti, DD. Procurador da Justiça, neste ato representando o Sr. Procurador Geral da Justiça, a quem também quero agradecer as palavras proferidas a meu respeito.

Minhas Senhoras,

Meus Senhores.

Todos nós temos, no correr de nossas vidas, momentos marcantes. Momentos que se erigem em símbolo de uma existência, precisamente porque refletem, em si, a singularidade de uma personalidade, e sua própria realização, e denota a terceira dimensão do homem que Cassirer descreve como o sistema simbólico, porque não se está mais no universo meramente físico, mas no universo simbólico, não do homem apenas como animal racional, mas do homem simbólicum. É com esse pensamento, Senhor Presidente, que recebo o Colar do Mérito Judiciário, que esse Tribunal me outorga. Aqui destaco que este é um momento marcante em minha vida, simbólico para mim, porque me foi conferido, ainda na gestão do Eminente Desembargador Dirceu de Melo, a quem saúdo neste instante, ou seja, logo após deixar a Secretaria de Segurança Pública do Estado de

1. Este discurso foi realizado no dia 17 de dezembro de 1999 no Palácio da Justiça Costa Manso, São Paulo. 
São Paulo, que esteve sob minha responsabilidade durante quatro anos e um mês. Uma gestão, talvez controvertida porque aí o homem mostrou coerência com seus princípios. O Colar do Mérito Judiciário que Vossas Excelências acabam de me conceder me dá a certeza de que, ao fim e ao cabo, foi uma luta bonita e compensadora, sobretudo, porque, em nenhum momento, abri mão da dignidade pessoal e de princípios que aprendi, não tanto nas escolas que freqüentei, não na Universidade que me deu muito, boa como ela é, nem mesmo foi nos livros que aprendi o respeito à dignidade da pessoa humana e o culto à liberdade. Tais princípios aprendi-os como o povo simples de minha terra, nos sertões mineiros. Ah, foram esses largos horizontes que me deram o sentido da liberdade; foi o jeito de viver digno dessa gente nossa que me entranhou a idéia de que cidadania não é, nem pode ser, um nome vão, de mera retórica política, porque há de ser a consciência de pertinência à sociedade como síntese dos direitos fundamentais do homem, com igual consciência de que essa situação subjetiva envolve também deveres de respeito à dignidade do outro e de contribuir para o aperfeiçoamento de todos.

Este é um momento de festa. Não é a hora de pronunciamentos ásperos. Mas toda hora é hora de defender a democracia e as instituições democráticas. Temo muito pelos acontecimentos. Vejo com muita preocupação certas atitudes em desrespeito ao Supremo Tribunal Federal. Não há, na democracia, poder incontrastável. Não há processos constitucionais do devido processo legal, do contraditório e da ampla defesa, com a necessária presença de Advogado, por conseqüência, porque todo processo tem como conteúdo conflitos de interesse e, nos regimes democráticos em que o monopólio da jurisdição pertence ao Poder Judiciário, só esse tem legitimidade, em última instância, para solucionar tais conflitos, restaurando o equilíbrio, mormente se o conflito se dá com o próprio Poder Público. E se se instaura a desobediência, não se saberá, no final das contas, a quem cabe a solução e aí o caminho tem sido historicamente o da ditadura.

Não quer dizer que não se deva realizar mudanças sérias no Poder Judiciário. Estamos todos conscientes de que a reforma do Judiciário é um reclamo para a aplicação do princípio da justiça igual para todos, segundo uma concepção moderna de que o Poder Judiciário é sede da cidadania. Mas uma reforma judiciária não pode ter apenas a preocupação de aliviar o Poder Judiciário da carga de trabalho que o assoberba, mediante formas de afastar de sua apreciação interesses que procuram amparo jurisdicional. Se há situações que comportam restrições, como o número excessivo de recursos e a insistência do Poder Público em recorrer ao 
Judiciário com causas sucessivamente perdidas, o certo é que a tomada de consciência pela cidadania de seus direitos tende a buscar no Judiciário a sua satisfação, e essa é uma busca legítima, que não pode ser tolhida. Qualquer reforma, pois, do Judiciário, para ser legítima, há de estar fundamentada na ampliação do acesso da cidadania à Justiça, da melhoria dos serviços judiciários, da realização do processo justo. Do contrário, será um novo engodo ao povo.

Encerro aqui, Senhor Presidente, porque essas questões ásperas não abrilhantam a festa, que deve ser sobretudo de agradecimento pela honrosa distinção, tanto mais honrosa, para mim, que a recebo juntamente com esse nobre homem público, que deu tanto de si para este Estado que é o Dr. Virgílio Lopes da Silva, tanto mais honrosa, Senhor Presidente, quanto a recebo numa solenidade deste Egrégio Tribunal de Justiça, sob a presidência de um destacado colega de turma, daqueles bons tempos, não só de nós estudantes, mas deste País, quando transcorriam os alegres anos da década de cinqüenta, quando, então, a moçada de saias longas e cabelos curtos passeavam sua beleza alegre por debaixo daquelas Arcadas solenes. E nós outros com nossas gravatas esvoaçantes, às vezes espalhafatosas, a resolver, nos corredores da Academia, todos os problemas do País, com essa maravilhosa empáfia, tão ingênua, quanto altiva daqueles que ainda não sabem que o sábio é aquele que sabe que não sabe. Ah, mas e assim mesmo que se formam os espíritos ávidos do saber.

Encerro, Senhor Presidente, com profundos agradecimentos a Vossa Excelência e a esse Egrégio Tribunal pela honrosa distinção, e também com profundos agradecimentos Ilustre Desembargador Ricardo Brancato por suas palavras que recordam momentos enriquecedores para mim.

Peço ainda permissão, Senhor Presidente para saudar a turma de 1957, na pessoa de nossa colega, Profa. Ivette Senise Ferreira, DD. Diretora da Faculdade de Direito da USP, e da Profa. Ada Pellegrini Grinover, aqui representando o Magnífico Reitor de nossa Universidade de São Paulo.

Muitíssimo obrigado, Senhor Presidente, muitíssimo obrigado Senhores Desembargadores. 


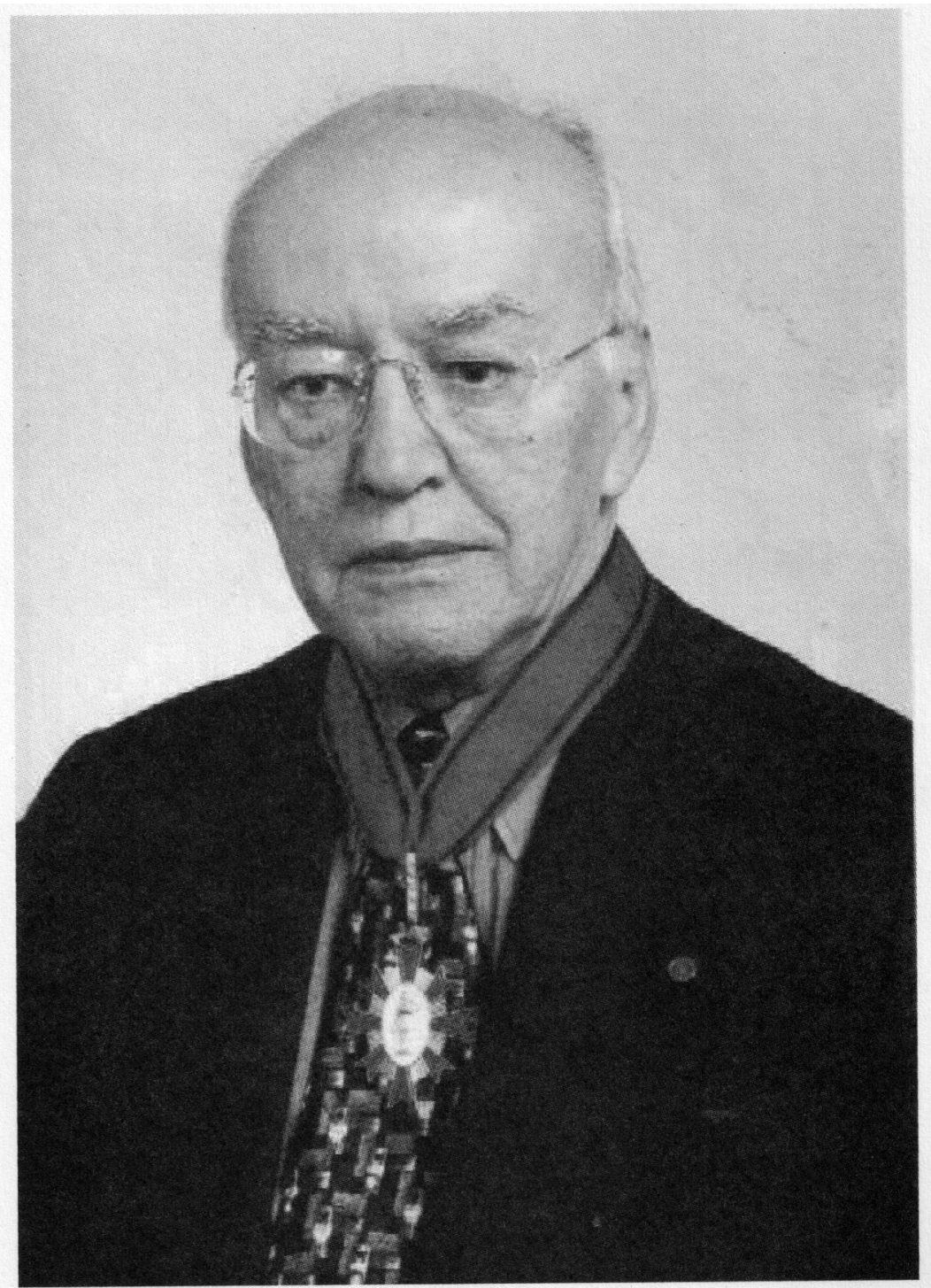

Professor Doutor José Afonso da Silva 